\title{
Violaciones al Código Internacional de Comercialización de Sucedáneos de Leche Materna en México
}

\author{
Violations of the International Code of \\ Marketing of Breastmilk Substitutes in \\ México.
}

En nuestro país, a pesar de los grandes beneficios de la lactancia materna para la salud de las futuras generaciones, ésta se redujo de $22,3 \%$ en 2006 a $14,5 \%$ en $2012^{1}$ y aunque recientemente, con las acciones de la Estrategia Nacional de Lactancia Materna se ha conseguido mejorar la lactancia materna a $30.8 \%$ en $2015,^{2}$ este indicador aún dista mucho de la meta global.

El aumento en el consumo de fórmulas y la comercialización inadecuada de sucedáneos son factores que desalientan la práctica de la lactancia materna; no obstante, que nuestro país, desde 1982, adoptó el Código Internacional de Comercialización de Sucedáneos de la Leche Materna (CICSLM), para limitar prácticas inadecuadas de mercadeo; la vigilancia de su cumplimiento sigue siendo un reto.

En 2015, nuestro país fue invitado por la Red Mundial para el Monitoreo y el Apoyo de la Adhesión al Código (NetCode, por sus siglas en inglés, establecida por la Organización Mundial de la Salud) a participar en la aplicación de un nuevo protocolo de monitoreo y evaluación del nivel de cumplimiento del CICSLM. Reciente- mente, el estudio se concluyó, siendo México el primero de 8 países, por lo que se comentan los resultados brevemente.

El estudio ejecutado por el Instituto Nacional de Salud Pública en dos Entidades Federativas se realizó bajo el liderazgo y coordinación de la Subsecretaría de Prevención y Promoción de la Salud a través del Centro Nacional de Equidad de Género y Salud Reproductiva, con apoyo financiero y técnico de la Organización Mundial de la Salud, la Organización Panamericana de la Salud y el Fondo para la Infancia de las Naciones Unidas (UNICEF).

El estudio se conformó de tres componentes:

\section{1) Unidades de salud y puntos de venta}

En 48 unidades de salud públicas y privadas se entrevistaron a 693 madres de menores de 24 meses y personal de salud, para recolectar información actual y de seis meses previos, sobre recomendaciones, muestras y publicidad de empresas productoras de sucedáneos. Se encontró que: 
- El $46 \%$ de las madres recibió recomendaciones de alimentar a su hijo(a) con algún sucedáneo.

- La fórmula de inicio fue el producto más recomendado (69\%).

- El médico fue la principal figura en recomendarlo (66\%) (Figura 1).

- Más de 10\% había recibido muestras de sucedáneos.

- El 8.5\% recibió algún regalo sobre sucedáneos o biberones.

- Médicos y representantes de empresas son quienes en su mayoría entregaron muestras de sucedáneos (Figura 2).

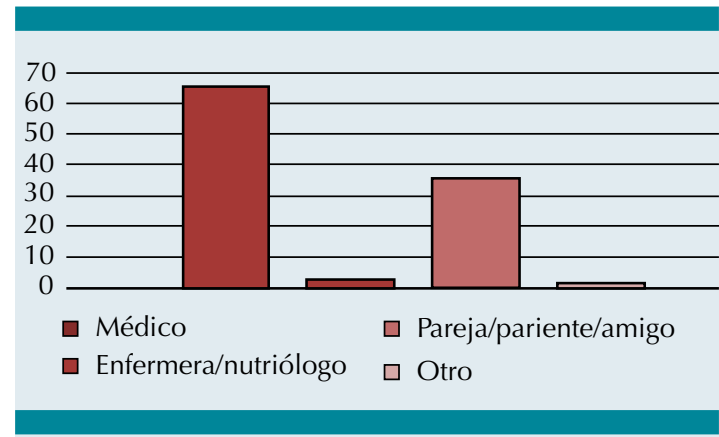

Figura 1. ¿Quién recomienda el uso de sucedáneos?
- En consultorios y hospitales privados se encontró el mayor número de violaciones por recomendación y entrega de muestras de sucedáneos.

- En 52\% de las unidades de salud se encontró publicidad, principalmente carteles.

- Más de $80 \%$ de las madres había visto publicidad de sucedáneos en medios de comunicación.

- Entre 40-55\% de personal de salud tenia conocimientos del CICSLM y las medidas nacionales para su implementación aunque más de $90 \%$ tenía capacitación reciente en lactancia materna.

\section{2) Evaluación de etiquetas e insertos}

Con base en una lista de productos inventariados, se acudió a 51 puntos de venta cercanos a las unidades de salud seleccionadas. Se fotografiaron o adquirieron los productos para evaluar el contenido de la información en la etiqueta o inserto, encontrando que:

- Más de 90\% de las etiquetas de fórmulas infantiles analizadas no cumplían con el

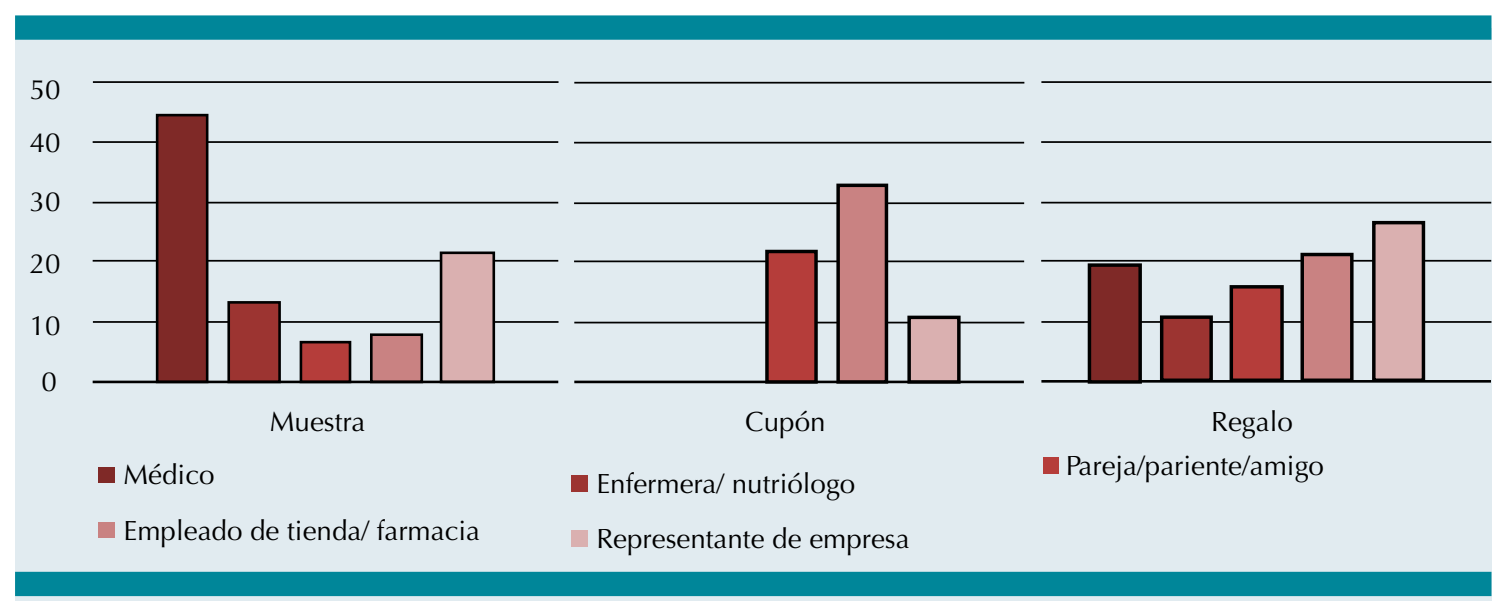

Figura 2. Distribución de muestras, cupones o regalos de empresas de sucedáneos. 
CICSLM, ya que el texto o imagen idealiza el uso de sucedáneos.

- Más de $10 \%$ no declaran la superioridad de la lactancia materna.

- El 30\% de los alimentos para menores de 24 meses no cumplían con CICSLM por incluir imágenes o texto que idealiza el uso de biberón o chupón.

\section{3) Monitoreo de la publicidad en televisión abierta e internet}

Se identificaron las páginas web y redes sociales de empresas comercializadoras de sucedáneos en México, así como los cuatro principales canales de televisión abierta, para evaluar la información e imágenes presentadas, promociones y contacto con el público. Se encontraron incumplimientos al CICSLM en contenido, textos e imágenes; además de gran presencia de productos para menores de 24 meses con imágenes y leyendas engañosas o que incitan al uso de sucedáneos.

\section{CONCLUSIONES}

El estudio demostró que existen múltiples violaciones al CICSLM y a las medidas nacionales para su implementación, dispuestas en el Reglamento de Control Sanitario de Productos y Servicios y en el Reglamento de la Ley General de Salud en materia de Publicidad.

Se requiere fortalecer las acciones de difusión y vigilancia al cumplimiento del CICSLM establecidas en la Estrategia Nacional de Lactancia Materna, así como incrementar las unidades de salud con la nominación: "Amigo del niño y la niña", que deben cumplir con CICSLM.
Es indispensable, sensibilizar y contar con el compromiso de pediatras, obstetras, enfermeras y demás personal de salud, para cumplir las disposiciones del CICSLM y resoluciones posteriores y las medidas nacionales, con el fin de evitar sanciones.

\section{REFERENCIAS}

1. Gutiérrez JP, Rivera-Dommarco J, Shamah-Levy T, VillalpandoHernández S, Franco A, Cuevas-Nasu L, et al, Encuesta Nacional de Salud y Nutrición 2012. Resultados Nacionales. Cuernavaca, México: Instituto Nacional de Salud Pública, 2012.

2. Instituto Nacional de Salud Publica y UNICEF México 2016. Encuesta Nacional de Niño, Niñas y Mujeres 2015-. Ciudad de México, México: Instituto Nacional de Salud Publica y UNICEF, México, 2016.

Dra. Erika Paola García Flores Subdirectora de Atención al Recién Nacido y

Prevención de la Discapacidad Centro Nacional de Equidad de Género y Salud Reproductiva Secretaria de Salud

Dra. Nazarea Herrera Maldonado Directora General Adjunta de Salud Materna y Perinatal

Centro Nacional de Equidad de Género y Salud Reproductiva Secretaria de Salud

Dra. Liliana Martínez Peñafiel Directora de Atención a la Salud Materna y Perinatal

Centro Nacional de Equidad de Género y Salud Reproductiva Secretaria de Salud

Dr. Eduardo Pesqueira Villegas

Director General del Centro Nacional de Equidad de Género y Salud Reproductiva Correspodencia: Erika Paola García Flores erika.garcia@salud.gob.mx neonatosalud@gmail.com 